\title{
EFEITO DO PROBIÓTICO COM OU SEM ZINCO E CÁLCIO NA CONCENTRAÇÃO SÉRICA DE ZINCO EM OVINOS
}

Renato Zanetti Todo ${ }^{1}$, Jakeline Poliane Pereira Donadeli ${ }^{1}$, Helena Fabiana Reis de Almeida Saraiva ${ }^{1}$, Luciana Alvares Calvo Penha ${ }^{1}$, Paulo Eduardo Pardo ${ }^{2}$, Rogério Giuffrida ${ }^{2}$, Sandra Cristina Genaro ${ }^{2}$.

${ }^{1}$ Alunos de graduação do Curso de Medicina Veterinária - UNOESTE - Presidente Prudente, SP. ${ }^{2}$ Docentes da Universidade do Oeste Paulista - UNOESTE - Presidente Prudente, SP.

\section{RESUMO}

O objetivo deste estudo foi avaliar o efeito da adição de probiótico com ou sem Ca e Zn na mistura mineral sobre a concentração sérica de $\mathrm{Zn}$ em ovinos. A adição de probióticos contendo $\mathrm{Ca}$ e $\mathrm{Zn}$ resultou na redução da concentração sérica de $\mathrm{Zn}$ em relação aos grupos Gc e GP, respectivamente. Não houve diferença significativa $(p<0,05)$ entre os grupos e dias de observação, portanto a adição de elementos minerais aos probióticos torna-se prejudicial à saúde dos ovinos, podendo predispor os animais a apresentar deficiências subclínicas e/ou clínicas de um determinado mineral ao longo do tempo da utilização destes produtos.

Palavras-chave: probiótico, zinco, ovino

\section{EFFECT OF THE PROBIOTIC, WITH OR WITHOUT ZINC AND CALCIUM, ON THE SERUM ZINC CONCENTRATION IN SHEEP}

\begin{abstract}
The aim of this study was to evaluate the effect of adding probiotics with or without $\mathrm{Ca}$ and $\mathrm{Zn}$ in the mineral mixture on the serum concentration of $\mathrm{Zn}$ in sheep. The addition of probiotics containing $\mathrm{Ca}$ and $\mathrm{Zn}$ resulted in a reduction in serum $\mathrm{Zn}$ in relation to groups $\mathrm{GP}$ and $\mathrm{Gc}$, respectively. There was no significant difference $(p<0.05)$ between groups and days of observation, so the addition of mineral elements to probiotics becomes detrimental to the health of sheep, which can predispose animals to produce subclinical deficiencies and / or a clinical certain mineral over time the use of these products.
\end{abstract}

Keywords: probiotics, zinc, sheep 


\section{INTRODUÇÃO}

O zinco $(Z n)$ é um microelemento mineral essencial para as funções fisiológicas dos organismos dos animais, participa de mais de duzentos sistemas enzimáticos no organismo e atua no metabolismo de ácidos graxos e proteínas, integridade das membranas das hemácias, síntese de DNA, da regulação do apetite, integridade do epitélio e dos ossos, sistema imunológico, reprodução e crescimento (PARDO et al.2004;HADDAD e ALVES, 2006).

$O$ cálcio $(\mathrm{Ca})$ é o elemento mineral mais abundante no organismo e essencial para a formação dos ossos e dos dentes, para a contração muscular, coagulação sanguínea e ativação de sistemas enzimáticos (HADDAD e ALVES, 2006).

Os probióticos são microrganismos vivos que se, administrados em quantidades adequadas, conferem benefícios à saúde do hospedeiro atuando como estimuladores do sistema imune e promotor do crescimento (ARENAS et al., 2007, PARDO e REIS,2008).

A absorção intestinal de $\mathrm{Zn}$ pode ser reduzida pelo excesso de Ca na alimentação pela presença de ácido fítico que se liga ao $\mathrm{Zn}$ formando um complexo fitato de $\mathrm{Zn}$ (PARDO et al. 2004, HADDAD e ALVES, 2006). No entanto, pouco se sabe sobre o efeito da administração de probiótico na concentração sérica de $\mathrm{Zn}$ em ovinos. Assim, o objetivo deste estudo foi avaliar o efeito da adição de probiótico com ou sem Ca e $\mathrm{Zn}$ na mistura mineral sobre a concentração sérica de $\mathrm{Zn}$ em ovinos.

\section{MÉTODOS}

Foram utilizados ovinos, fêmeas, com aproximadamente 6 meses de idade, mestiço Santa Inês, animais não prenhes, vermifugados pertencentes a um plantel no município de Taciba, a uma latitude $22^{\circ} 23^{\prime} 23^{\prime \prime}$ sul e a uma longitude $51^{\circ} 17^{\prime} 05^{\prime \prime}$ oeste, estando a uma altitude de 416 metros. Os animais foram mantidos em pastagem de capim Aruana, em sistema de pastejo extensivo e divididos randomicamente em três grupos (15 animais/grupo): grupo controle, em que os ovinos foram suplementados com mistura mineral sem adição de probiótico, um segundo grupo que recebeu mistura mineral adicionada com probiótico sem $\mathrm{Zn}$ e $\mathrm{Ca}$ (denominado de grupo GP) e no terceiro grupo os ovinos receberam suplemento mineral adicionado de probiótico contendo $\mathrm{Ca}$ e $\mathrm{Zn}$ (denominado de grupo $\mathrm{GP}_{\mathrm{Ca}+\mathrm{Zn}}$ ).

A mistura mineral utilizada em todos os grupos experimentais foi a Fort Sal Ovinos ${ }^{\circledR}$ que era composta por (em cada $\mathrm{Kg}$ de suplemento): $140 \mathrm{~g}$ de Ca; $65 \mathrm{~g}$ de fósforo; $100 \mathrm{~g}$ sódio; $11 \mathrm{~g}$ de magnésio; $6.000 \mathrm{mg}$ de zinco; $1.100 \mathrm{mg}$ de manganês; $2.000 \mathrm{mg}$ de ferro; $135 \mathrm{mg}$ de cobalto; $195 \mathrm{mg}$ de iodo; $30 \mathrm{mg}$ de selênio; $20 \mathrm{mg}$ de níquel. Nesta mistura mineral descrita acima foram adicionados probiótico sem $\mathrm{Zn}$ e $\mathrm{Ca}$ e probiótico contendo $\mathrm{Zn}$ e $\mathrm{Ca}$. O consumo médio de todos os suplementos minerais foi de 10 g/animal/dia.

O probiótico sem adição de $\mathrm{Ca}$ e $\mathrm{Zn}$ utilizado no experimento era composto por (níveis de garantia/Kg de produto): $25 \mathrm{~g}$ de enxofre; $10 \mathrm{~g}$ de cobalto; Bacillus 2.220.000.000 unidade formadora de colônia (ufc); Streptococcus faecium 2.220.000.000 ufc; Lactobaccilus 2.220.000.000 ufc; Bifeddobacterium 2.220 .000 .000 ufc e veiculo q.s.p. $930 \mathrm{~g}$.

O probiótico contendo $\mathrm{Ca}$ e $\mathrm{Zn}$ utilizado no experimento era composto por (níveis de garantia/Kg de produto): $35 \mathrm{~g}$ de cálcio; $25 \mathrm{~g}$ de enxofre; $10 \mathrm{~g}$ de cobalto e $3.600 \mathrm{mg}$ de zinco; Bacillus 2.220.000.000 ufc; Streptococcus faecium 2.220.000.000 ufc; Lactobaccilus 2.220.000.000 ufc; Bifeddobacterium 2.220.000.000 ufc e veiculo q.s.q. $930 \mathrm{~g}$. 
O consumo de ambos os probióticos descritos acima foram de $4 \mathrm{~g} / \mathrm{ovino} / \mathrm{dia}$, segundo Arenas et al.(2009).

A ingestão de $\mathrm{Ca}$ e $\mathrm{Zn}$ pelos ovinos foram determinadas conforme preconizado por Haddad e Alves (2006) onde relataram que em condições brasileiras, de campo e sem ingestão de água em cacimba, sem concentração excessiva de nutrientes na água e em regime exclusivo de pasto, foi determinada a ingestão de minerais pela concentração do elemento mineral na pastagem somada com a concentração do elemento mineral no suplemento mineral.

Os dados apresentaram distribuição normal no teste de Kolmogorov e Smirnov. Assim, as médias de concentrações séricas de zinco entre os grupos foram comparadas pela Análise de Variância e entre os dias zero e 60 aplicou-se o teste $t$ para amostras pareadas (PAGANO e GAUVREAU, 2004).

De todos os animais que constituíram os 3 grupos foram colhidas amostras de sangue, mediante punção jugular, com agulhas $25 \times 7$, diretamente em tubo de $4,5 \mathrm{~mL}^{1}$ e contendo anticoagulante (Sal de Sódio do ácido etilenodiamino tetra-acético), nos dias 0,30 e 60 . Os frascos foram identificados, conforme 0 número de cada animal, sendo acondicionados em caixa térmica, contendo gelo e transportados para o laboratório do Hospital Veterinário da Universidade do Oeste Paulista - Presidente Prudente - SP, onde foram centrifugados por 10 minutos, a 2.500 rotações/minuto e retirado o sobrenadante. As amostras obtidas foram envasadas em tubos de $1,5 \mathrm{~mL}^{2}$ e identificados quanto ao animal e data de colheita e mantidos em freezer a $-20^{\circ} \mathrm{C}$. A metodologia utilizada para determinação da concentração do zinco sérico, foi descrita por (PARDO, 2004).

\section{RESULTADOS}

As amostras de capim Aruana colhidas dos três piquetes pastejados pelos ovinos tinha a concentração de $14 \mathrm{mg}$ de $\mathrm{Zn} / \mathrm{Kg}$ e de $3,1 \mathrm{~g}$ de $\mathrm{Ca} / \mathrm{Kg}$. Na água de bebida dos animais a concentração de $\mathrm{Zn}$ era de 5,54 $\mu \mathrm{g}$ de $\mathrm{Zn} / \mathrm{L}$. Observa-se na Figura 1 que não houve diferença significativa na concentração sérica de $\mathrm{Zn}$ entre os grupos experimentais e dias de observação.

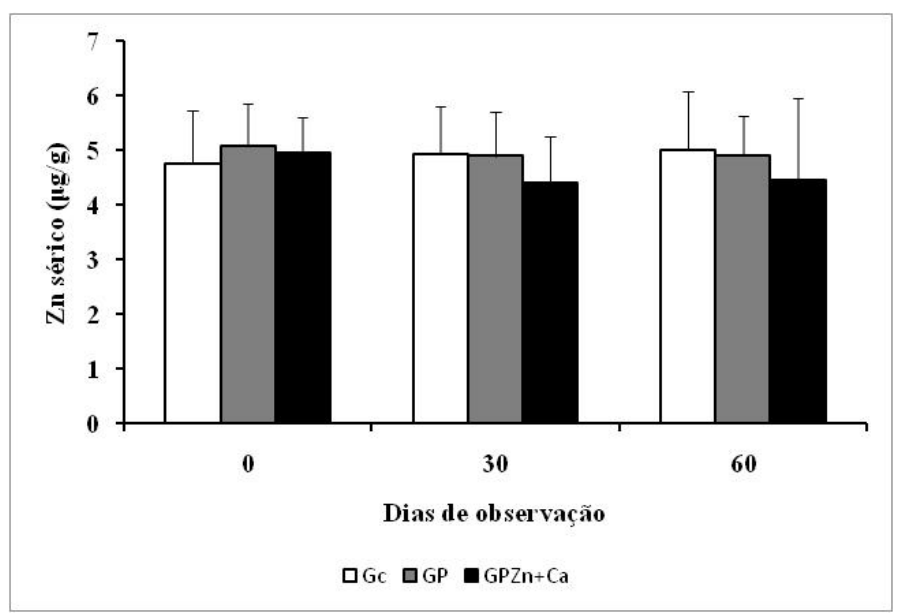

Figura 1- Médias das concentrações séricas de zinco ( \pm desvio padrão) de ovinos mestiços Santa Inês sem suplementação de probiótico (Gc), suplementado com probiótico sem Zn e Ca (GP) e suplementado com probiótico contendo $\mathrm{Zn}$ e $\mathrm{Ca}$ $\left(G P_{C a+Z n}\right)$. Não houve diferença significativa na concentração sérica de $\mathrm{Zn}$ entre os grupos experimentais e nem entre os dias de observação.

\section{DISCUSSÃO}

O capim Aruana dos três piquetes apresentaram concentrações semelhantes de $\mathrm{Zn}$ (14 ppm) e Ca $(3,7 \mathrm{~g} / \mathrm{Kg})$. Esta concentração de $\mathrm{Zn}$ era deficiente para estes animais, pois o NRC (1985) recomenda que a dieta dos ovinos em crescimento e engorda deve conter 20 ppm de $\mathrm{Zn}$. Ainda mais, a rotação de piquetes dos ovinos a cada 30 dias proporcionou as mesmas condições de pastejo para todos os grupos experimentais. Portanto, as condições experimentais garantiram que as variações nas concentrações séricas $\mathrm{Zn}$ observada nos ovinos

\footnotetext{
${ }^{1}$ VACUTAINER ${ }^{\circledR}$

${ }^{1}$ EPPENDORF ${ }^{\circledR}$
} 
foram obtidas exclusivamente em função dos tratamentos.

Nos ovinos grupo Gc, que receberam dieta contendo 5,1 $\mathrm{g}$ de $\mathrm{Ca} / \mathrm{Kg}(3,7 \mathrm{~g}$ de $\mathrm{Ca}$ da forragem mais $1,4 \mathrm{~g}$ da mistura mineral) e $20 \mathrm{mg}$ de $\mathrm{Zn} / \mathrm{Kg}$ (14 mg de $\mathrm{Zn}$ da forragem mais $6 \mathrm{mg}$ do suplemento mineral) conforme recomendada pelo NRC (1985) e receberam mistura mineral sem adição de probiótico, a concentração séria de Zn aumentou $6,16 \%$ ao longo do período experimental. Apesar de não ter apresentado diferença significativa entre os dias de observação (Figura 1), nota-se o efeito biológico, que a dieta contendo $20 \mathrm{mg}$ de $\mathrm{Zn} / \mathrm{Kg} \mathrm{com}$ a relação $\mathrm{Ca}: \mathrm{Zn}$ de 1:3,92 foram eficientes para a concentração sérica de $\mathrm{Zn}$ dos ovinos da raça Santa Inês.

Os animais do grupo GP receberam a dieta contendo as mesmas concentrações de $\mathrm{Ca}$ (5,1 $\mathrm{g}$ de $\mathrm{Ca} / \mathrm{Kg}$, sendo $3,7 \mathrm{~g}$ de $\mathrm{Ca}$ da forragem mais $1,4 \mathrm{~g}$ da mistura mineral), Zn (20 ppm de Zn, sendo $14 \mathrm{ppm}$ de $\mathrm{Zn}$ da forragem mais $6 \mathrm{ppm}$ do suplemento mineral) conforme recomendada pelo NRC (1985) e relação Ca:Zn (1:3,92) semelhantes à do grupo Gc, mas foi adicionado probiótico sem $\mathrm{Ca}$ e $\mathrm{Zn}$ à mistura mineral, resultando em concentração sérica de Zn 2\% menor que a do Gc e ainda diminuiu 2,97\% ao longo do período experimental. Embora, não tenham sido detectadas diferenças significativas entre os grupos e dias de observação (Figura 1), observam-se o efeito biológico da adição do probiótico, que há indícios que os microrganismos contidos nestes produtos podem estar interferindo no metabolismo ruminal e na absorção de $\mathrm{Zn}$.

No grupo $\mathrm{GP}_{\mathrm{Ca}+\mathrm{Zn}}$ que os ovinos receberam dieta contendo concentrações de $\mathrm{Ca}$ (5,24 g de $\mathrm{Ca} / \mathrm{Kg}$, sendo 3,7 g de Ca da forragem mais $1,4 \mathrm{~g}$ da mistura mineral mais $0,14 \mathrm{~g}$ do probiótico), Zn (34,4 mg de Zn/Kg, sendo $14 \mathrm{mg}$ $\mathrm{Zn}$ da forragem mais $6 \mathrm{mg} \mathrm{Zn}$ do suplemento mineral e mais $14,40 \mathrm{mg}$ do probiótico), sendo que a dose de $Z n$ está 72\% acima da recomendada (20 $\mathrm{mg}$ de $\mathrm{Zn} / \mathrm{kg}$ ) pelo NRC (1985) e relação a Ca:Zn foi de 1:6,56 semelhantes. Portanto, a adição de probiótico contendo $\mathrm{Ca}$ e $\mathrm{Zn}$ causou o desbalanceamento nutricional de $\mathrm{Zn}$ resultando na redução da concentração sérica de Zn de $11 \%$ e $9,18 \%$ em relação aos grupos Gc e $\mathrm{GP}$, respectivamente, ainda mais, o $\mathrm{Zn}$ sérico também diminuiu $11,18 \%$ entre os dias 0 e 60 , mesmo assim, não houve diferença significativa entre os grupos e dias de observação (Figura 1). Portanto, provavelmente a adição de elementos minerais aos probióticos torna-se prejudicial à saúde dos ovinos, podendo predispor os animais a apresentar deficiência subclínica e/ou clínica de um determinado mineral ao longo do tempo de utilização destes produtos.

\section{REFERÊNCIAS}

ARENAS, S.E.; REIS, L.S.L.S.; FRAZATTIGALLINA, N.M.; GIUFFRIDA, R.; PARDO, P.E. Efeito do probiótico proenzime ${ }^{\circledR}$ no ganho de peso em bovinos. Arch. Zootec., v.56, n.213, p.75-78, 2007.

HADDAD, C.M.; ALVES, F.V. Minerais para gado de corte. In: BITTAR, C.M.; MOURA, J.C.; FARIA, V.P.; MATTOS, W.R.S. Minerais e aditivos para bovinos; Anais ... Piracicaba: FEALQ, 2006 p.63-76.

NATIONAL RESEARCH COUNCIL. Nutrient Requirements and Signs of Deficiency. In:

(Eds.). Nutrient requerements of sheep. Washington: National Academy Press, 1985. p.225.

PAGANO, M., GAUVREAU, K. Princípios de bioestatística. 2 ed. São Paulo: Pioneira Thomson Learneing, 2004

PARDO,P.E;BREMER NETO,H; PADILHA,P.M;NAGOSHI,M;CHIACCHIO,S.B.

Determinação de zinco da sola do casco de 
bovinos leiteiros com ou sem lesões podais, suplementados ou não com levedura seca de cana-de-açucar. Ciência Rural, V.34,n.5,p.15011504.

PARDO,P. E.; REIS,L.S.LS. Nutrientes e Nutracêuticos em Grandes Animais. In: ANDRADE,S.F. Manual de Terapêutica Veterinária, 3ed. São Paulo: Editora Roca. LTDA, 2008. Capítulo 29, p808-814

PARDO,P. E. Deteminação do zinco plasmático e da sola do casco de bovinos leiteiros com ou sem lesões podais, suplementados ou não com levedura seca de cana-de- açúcar. Ciência Rural, Santa Maria, v. 34, n.5, p.1501, set-out, 2004. 